\title{
WCST and NEUPSILIN: Relationships among Executive Functions, Attention, Memory and Language
}

\author{
WCST e NEUPSILIN: Relações entre Funções Executivas, Atenção, \\ Memória e Linguagem
}

\author{
Denise Balem Yates ${ }^{a}$, Murilo Ricardo Zibetti ${ }^{a}$, Josiane Pawlowski $^{b}$, Jerusa Fumagalli Salles ${ }^{a}$, \\ Maria Alice de Mattos Pimenta Parente ${ }^{c}$, Irani de Lima Argimon ${ }^{d}$, Rochele Paz Fonseca ${ }^{d}$ \\ \& Clarissa Marceli Trentini*,a \\ ${ }^{a}$ Universidade Federal do Rio Grande do Sul, Porto Alegre, Rio Grande do Sul, Brasil, \\ ${ }^{b}$ Universidade Federal do Rio de Janeiro, Rio de Janeiro, Rio de Janeiro, Brasil, \\ ${ }^{c}$ Universidade Federal do ABC, Santo André, São Paulo, Brasil \\ \& 'Pontifícia Universidade Católica do Rio Grande do Sul, Porto Alegre, Rio Grande do Sul, Brasil
}

\begin{abstract}
This study investigated the relationship between measures of the Wisconsin Card Sorting Test (WCST) and a brief battery of cognitive functions (NEUPSILIN) with the goal of providing a better understanding of the association between executive processes and other functions. The sample included 39 people, from 14 to 61 years old, with an average education of $12.38(S D=3.65)$ years of study. The hypothesis that correlations would be moderate to strong between the measures of executive function, working memory, attention and prospective memory from NEUPSILIN and WCST scores was partially corroborated because the intensity of the correlations was below than the expected. Other correlations were also found between the WCST scores and tasks that assess semantic-episodic memory, oral language (inference processing) and writing (reading) components.

Keywords: Executive functions, cognition, neuropsychology, WCST, NEUPSILIN.

\section{Resumo}

Este estudo investigou a relação entre medidas do WCST e de uma bateria breve de funções cognitivas (NEUPSILIN), com o objetivo de fornecer uma melhor compreensão sobre a associação entre processos executivos e demais funções. Participaram 39 pessoas entre 14 e 61 anos de idade e média de escolaridade de 12,38 $(D P=3,65)$ anos de estudo. A hipótese de que correlações moderadas a fortes se dariam entre as medidas de funções executivas, memória de trabalho, atenção e memória prospectiva do NEUPSILIN e os escores no WCST foi parcialmente corroborada, porque a intensidade das correlações foi inferior ao previsto. Também foram encontradas correlações entre escores do WCST e tarefas que mensuram componentes de memória episódico-semântica, linguagem oral (processamento inferências) e escrita (leitura).

Palavras-chave: Funções executivas, cognição, neuropsicologia, WCST, NEUPSILIN.
\end{abstract}

The executive functions (EF) construct has received increasing attention from several areas such as cognitive psychology and neuropsychological evaluation. This results from its complexity, multi-dimensionality and wide relationship with other cognitive functions (for a review, see Verdejo-García \& Bechara, 2010). In this context, classic instruments for executive functions assessment, like the Wisconsin Card Sorting Test (WCST), must be better

\footnotetext{
${ }^{*}$ Mailing address: Av. Ramiro Barcelos, 2600, sala 119, Porto Alegre, RS, Brasil 90035-003. E-mail: clarissatrentini@terra.com.br

The authors thank the students who assisted in the data collection of this article: Camila Rosa de Oliveira, Francéia Veiga Liedtke, Jaqueline de Carvalho Rodrigues e Letícia Leuze Machado.
}

understood in terms of specific subcomponents which underlie its operation. This study investigated the relationship between the WCST and a brief battery of cognitive functions evaluation, the Brazilian Brief Neuropsychological Assessment Battery (NEUPSILIN), aiming to provide a more detailed understanding about the association between executive processes and other cognitive functions.

The WCST was developed in 1948 by Grant and Berg as an instrument to assess abstract reasoning, concepts formation and shift of cognitive strategies in response to environmental changes (Eling, Derckx, \& Maes, 2008). Nowadays, in Brazil, there are two different systems of WCST application and scoring. The standard version (Heaton, Chelune, Talley, Kay, \& Curtis, 1993), standardized for the population from 6 to 17 years old (Cunha et al., 
2005 ) and 60 to 89 years old (Trentini, Argimon, Oliveira, \& Werlang, 2010), and a modified version by Nelson (1976), standardized for the elderly from 70 to 73 years old (Ávila, 2007). In the standard version, one group of scores is generated and indicates the performance of the executive functions. Many researchers have investigated which functions would be related with each score and how they would relate to one another (Ashendorf \& McCaffrey, 2008; Cinan, 2006; Greve et al., 2002; Salthouse, 2005; Trentini \& Argimon, 2008).

Greve, Ingram and Bianchini (1998) presented a review of some studies which conducted factorial analysis of WCST results, aiming to find underlying constructs of the test. Although great variants were found in the samples, the major part of the investigations pointed to a two-factor solution. The first factor is related to mental flexibility and to the ability to recognize concepts and is composed of the following scores: conceptual level responses, number of completed categories, total number of correct responses, number of perseverative errors, number of perseverative responses and total number of errors (Greve et al., 1998). The second factor is related to memory (Bowey, Kammieny, Burns, \& Yahr, 1975, quoted by Greve et al., 1998), attention and motivation (Fey, 1951 quoted by Greve et al., 1998) and is composed of failure to maintain set and number of non-perseverative errors.

Several investigations using the neuroimaging paradigm also have been conducted with the aim of comprehending the WCST underlying processes (Fernandez-Duque \& Posner, 2001; Lie, Specht, Marshall, \& Fink, 2006). These studies have supported the idea that the performance in WCST involves a wide neural network which comprehends cortical structures as well as subcortical ones; each one making distinct and specific operations that are integrated in milliseconds. Lie et al. (2006) transformed the WCST into three specific variants which evaluated the WCST underlying processes. The authors observed that there were differences in areas and brain activation intensity within each variant used.

Therefore, a great body of evidence suggests that the WCST performance is mediated by underlying cognitive functions. That is why analyzing the relationship between the WCST and other tasks which evaluate several cognitive functions may help to comprehend the underlying processes of its performance. The current investigation also collaborates for a greater understanding of executive functions themselves, since there are several models that conceptualize them.

The predominant view about executive functions considers the term as a multi-dimensional behavioral concept with cortical subfunctions of superior order relatively independent, such as: goal directed behavior, attention control, temporal organization and planning (Ardila, 2008; Chan, Shum, Toulopoulou, \& Chen, 2008; Friedman \& Miyake, 2004; Hull, Martin, Beier, Lane, \& Hamilton, 2008; Lehto, Juujärvi, Kooistra, \& Pulkkinen, 2003; Miyake et al., 2000; Stuss \& Alexander, 2000). Although being predominant, this view is not unanimous since some authors consider the executive functions a unique entity (Duncan, Burgess, \& Emslie, 1995; Duncan, Emslie, Williams, Johnson, \& Freer, 1996; Salthouse, Atkinson, \& Berish, 2003).

Amongst the several theories on EF, the factorial model was of special interest in this study for understanding the WCST performance. In such a model, the executive functioning is conceived as having three independent, yet related, basic functions: Shifting, Inhibition and Updating (Miyake et al., 2000). These functions are required in different levels during the tests that evaluate the executive functioning. Shifting is also named attention switching or task switching, and requires irrelevant task abandonment and the subsequent engaging in a relevant task. The inhibition concept is restricted to intentional and controlled suppression of dominant, automatic and prepotent responses. Updating consists of renewing and monitoring the working memory representations (Engle, 2002; Lehto, 1996).

Considering the executive functions as moderately distinct abilities related, Blair, Zelazo, and Greenberg (2005) suggest that the working memory is one of the several executive functions that control cognitive performance. Other authors believe that there is an attention control construct common to executive function and working memory tasks, named executive attention (Kane \& Engle, 2000; McCabe, Roediger, McDaniel, Balota, \& Hambrick, 2010; McVay \& Kane, 2009). Several other terms have been used to describe the underlying ability to the performance in complex cognitive tasks, including executive control (Logan, 2003), attentional control (Balota et al., 1999), controlled attention (Engle, Tuholski, Laughlin, \& Conway, 1999), and cognitive control (Depue, Banich, \& Curran, 2006), among others.

Based on the executive attention construct (Kane \& Engle, 2000; McCabe et al., 2010; McVay \& Kane, 2009) and other complex cognitive tasks underlying abilities, like attention (Greve, Williams, Haas, Littell, \& Reinoso, 1996; McCabe et al., 2010), working memory (Cinan \& Tanör, 2002) and prospective memory (Nyhus \& Barceló, 2009), the objective of the present study was to verify if the performance obtained in WCST was related to those cognitive functions. The main hypothesis which directed this study was the possibility to find moderate to strong correlations between the WCST measures and these executive function tasks. Weak correlations might also occur between the WCST scores and other NEUPSILIN tasks, due to the influence of the executive abilities within other behavioral aspects (Lezak, Howieson, \& Loring, 2004) and the necessity of other functions preservation, such as language, for a good executive performance (Baldo et al., 2005).

\section{Method}

\section{Participants}

Participated in this study 27 women $(69.2 \%)$ and 12 men $(30.8 \%)$, from 14 to 61 years old $(M=38.79, S D=$ 
15.36) with an average education of $12.38(S D=3.65)$ full formal years of study. Participants with a history of illicit use of psychotropic drugs and benzodiazepine use, history of psychiatric disorders and/or self-reported neurological and not corrected sensory deficits were excluded.

\section{Instruments}

The instruments used in this study are briefly described below: (a) Socio-cultural and health questionnaire (Pawlowski, 2007): applied with the objective of verifying the excluding criteria by self-report, as well as the participants' characteristics such as age, gender, education, family and social aspects. (b) CAGE questionnaire (Mansur \& Monteiro, 1983): composed of four questions with the objective of identifying individuals who present problems related to alcohol use. Individuals who answered positively to two or more questions were excluded. (c) Wisconsin Card Sorting
Test (Cunha et al., 2005; Heaton et al., 1993): evaluates the cognitive flexibility and problem solving and is considered the golden standard of the executive functions evaluation (Delis, Kaplan, \& Kramer, 2001). The task consists of combining two decks of cards (64 cards each) with four stimuli cards. The examinee is instructed to combine the cards and receives feedback from the examiner about the success or failure of each association. The examinee's task consists of discovering the previous combination stipulated (category) and to make the response apply to each new context (examiner's new demand). The test ends when the examinee completes the six categories required (ten consecutive correct combinations) or when all the cards are used. For a presentation of WCST, see Miguel (2005).

The first group of norms of the WCST for the Brazilian population was developed by Cunha et al. (2005). The study had a sample of 515 participants from 6 to 17 years

Table 1

Description and Interpretation of the Wisconsin Card Sorting Test scores

\begin{tabular}{|c|c|c|}
\hline Score & Description & Interpretation \\
\hline $\begin{array}{l}\text { Total number of } \\
\text { trials administered }\end{array}$ & Total number of cards used. & $\begin{array}{l}\text { The lower the score, the greater the efficiency of the } \\
\text { examinee in the task. }\end{array}$ \\
\hline
\end{tabular}

Total number of Number of successes in combinations correct responses according to the current category.

Total number of Number of incorrect combinations, done errors

Perseverative responses

Perseverative Errors

Conceptual level responses

Number of completed categories

Trials to complete the first category despite the examiner's feedback.

Number of correct and incorrect combinations done by combining with a determined standard.

Number of incorrect combinations done by combining with an incorrect combination standard.

Consecutive correct answers which occur in a number of three or more.

Number of categories (each sequence of 10 consecutive correct combinations according to the classification criteria) which the examinee completes successfully along the test.

Number of attempts needed to complete the first category successfully.

Non-perseverative Number of errors which occur in a nonerrors perseverative way, that is, number of errors that do not persist in an incorrect combination standard.

Failure to maintain set
Number of times the examined individual makes five or more consecutive correct combinations, but makes an error before completing a category.
The greater the score, the better the performance (considering the number of trials administered).

The greater the score, the worse the performance.

The greater the score, the worse the performance.

The greater the score, the worse the performance. It indicates the mental inflexibility and insight difficulty.

The greater the score, the better the performance. It indicates insight about the correct principle of cards combination.

The greater the score, the better the performance in the task.

The greater the score, the greater the difficulty the examinee has to perceive the current category and combine accordingly.

The greater the score, the worse the performance. It indicates difficulties on forming concepts and having insights even with flexible answers.

The greater the score, the worse the performance on keeping the correct responses in sequence. 
Yates, D. B., Zibetti, M. R., Pawlowski, J., Salles, J. F., Parente, M. A. M. P., Argimon, I. L., Fonseca, R. P. \& Trentini, C. M. (2013). WCST and NEUPSILIN: Relationships among Executive Functions, Attention, Memory and Language.

old. Its clinical validity was verified through the comparison between a normative group and an Attention Deficit and Hyperactivity Disorder patient sample. Isolated, the variables do not discriminate the groups, although, when examined together, they are able to do so. The reliability of the WCST was evaluated through the generalizability theory. The generalizability coefficients of the WCST scores ranged from .66 to .75 , with a mean of .70, which demonstrates a satisfactory scale reliability for all scores (Cunha et al., 2005).

The WCST provides a series of scores, described on Table 1.

(d) Brazilian Brief Neuropsychological Assessment Battery NEUPSILIN (Fonseca, Salles, \& Parente, 2009): it is a brief battery of neuropsychological assessment composed of 32 tasks which examines components of eight neuropsychological functions - time and spatial orientation, sustained auditory attention, visual perception, memory (working, episodic, semantic, visual recognition and prospective), arithmetic abilities, language skills (oral and written in word and sentence levels), motor abilities (ideomotor, constructional and reflexive) and executive functions (consisting of two subcomponents: solving simple problems and verbal phonemic-spelling fluency). For a more detailed tasks and scores description, see Pawlowski, Fonseca, Salles, Parente and Bandeira (2008).

The evidence of this instrument's construct validity was indicated by scores differences in NEUPSILIN due to the variable years of study (Pawlowski et al., 2008). Those were also obtained by the correlation of the instrument scores with other tests that evaluated similar constructs, such as attention and intelligence (Fonseca et al., 2009). Furthermore, reliability evidence was obtained from testretest analyses, with a reliability index varying from .35 to .90 (Fonseca et al., 2009).

\section{Procedures}

This research was conducted according to ethical parameters for research with human beings and the main project has been approved by the Ethical Research Committee of the Federal University of Rio Grande do Sul (wide project of standardization and verification of psychometric standards). The data were collected individually and the instruments were applied by psychologists or psychology students who were properly trained. During the evaluation session, the first instrument applied was the socio-cultural and health questionnaire (Pawlowski, 2007), followed by the CAGE questionnaire (Mansur \& Monteiro, 1983), and lastly the following test order was alternated: half of the examinees did the WCST (Heaton et al., 1993; adaptation of Cunha et al., 2005) followed by the NEUPSILIN (Fonseca et al., 2009), and half of the examinees did the inverted order.

Descriptive analyses were conducted for the sample characterization, using the SPSS Program Version 18.0. The Kolmogorov-Smirnov test was conducted in order to verify the data normality. Due to the data non-normality, Spearman correlations (non-parametrical analyses) between the WCST scores and the NEUPSILIN scores were held. Correlations between .10 and .39 were considered weak, between .40 and .69 , moderate, and between .70 and .99 , strong (Dancey \& Reidy, 2006).

\section{Results}

Weak to moderate correlations between the WCST and NEUPSILIN measures, in the order of .3 to .5 , were found. The significant correlations $(p<.05)$ between the two instruments are shown in Table 2.

Moderate and negative correlations occurred between sustained attention (reverse counting) scores of NEUPSILIN and number of trials to complete the first category of WCST; between visual perception (face recognition) of NEUPSILIN and non-perseverative errors of WCST; working memory (ascendent ordering of digits) of NEUPSILIN and total number of trials administered, number of errors and perseverative errors of WCST, and between oral language scores (inferential processing) of NEUPSILIN and conceptual level responses and non-perseverative errors of WCST. Scores of working memory tasks (ascendent ordering of digits) of NEUPSILIN and non-perseverative errors and number of completed categories of WCST and oral language (inferential processing) of NEUPSILIN and conceptual level responses of WCST correlated moderately and positively.

Weak and negative correlations were found between the visual perception task (face recognition) of NEUPSILIN and number of trials and number of errors of the WCST; working memory (ascendent ordering of digits) of NEUPSILIN and perseverative responses of WCST; verbal episodic-semantic memory (delayed recall) and number of trials, total number of errors and trials to complete the first category of WCST; short-term visual memory of NEUPSILIN and perseverative errors of WCST; prospective memory of NEUPSILIN and failure to maintain set of WCST; oral language (inferential processing) of NEUPSILIN and number of errors of WCST; written language (reading aloud) of NEUPSILIN and total number of correct responses and failure to maintain set of WCST. The visual perception task (face recognition) of NEUPSILIN and number of completed categories of WCST, oral language (inferential processing) task of NEUPSILIN and number of completed categories of WCST, the verbal fluency task of NEUPSILIN and total number of correct responses and failure to maintain set of the WCST correlated weakly and positively.

\section{Discussion}

The initial hypothesis based on the construct of executive attention and on the literature about the relationships between the EF components measured by WCST and working memory was reinforced by the presented results. 
Table 2

Spearman Significative* Correlations between the WCST and NEUPSILIN scores.

\begin{tabular}{|c|c|c|c|c|c|c|c|c|c|c|}
\hline $\begin{array}{l}\text { WCST/ } \\
\text { NEUPSILIN }\end{array}$ & $\begin{array}{l}\text { Num. of } \\
\text { Trials } \\
\text { Adm. }\end{array}$ & $\begin{array}{c}\text { Total } \\
\text { Num. } \\
\text { Correct }\end{array}$ & $\begin{array}{l}\text { Total } \\
\text { Num. } \\
\text { Errors }\end{array}$ & $\begin{array}{l}\text { Perseve- } \\
\text { rative } \\
\text { Resp. }\end{array}$ & $\begin{array}{l}\text { Perseve- } \\
\text { rative } \\
\text { Errors }\end{array}$ & $\begin{array}{l}\text { Concept. } \\
\text { Level } \\
\text { Resp. }\end{array}$ & $\begin{array}{l}\text { Num. } \\
\text { Comp. } \\
\text { Cat. }\end{array}$ & $\begin{array}{l}\text { Trials to } \\
\text { complete } \\
1^{\text {st }} \text { Cat. }\end{array}$ & $\begin{array}{l}\text { Non-perse- } \\
\text { verative } \\
\text { Errors }\end{array}$ & $\begin{array}{c}\text { Failure to } \\
\text { maintain } \\
\text { set }\end{array}$ \\
\hline $\begin{array}{l}\text { Sustained } \\
\text { Attention: } \\
\text { Reverse count. }\end{array}$ & & & & & & & & -.463 & & \\
\hline $\begin{array}{l}\text { Visual } \\
\text { Perception: } \\
\text { Face recog. }\end{array}$ & -.317 & & -.337 & & & & .364 & & -.531 & \\
\hline $\begin{array}{l}\text { Working } \\
\text { Memory: } \\
\text { Ascendent } \\
\text { order. of digits }\end{array}$ & -.482 & & -.487 & -.394 & -.401 & & .417 & & .459 & \\
\hline $\begin{array}{l}\text { Verbal } \\
\text { Episodic- } \\
\text { semantic } \\
\text { Memory: } \\
\text { Delayed } \\
\text { recall }\end{array}$ & -.324 & & -.343 & & & & & -.340 & & \\
\hline $\begin{array}{l}\text { Short-Term } \\
\text { Visual } \\
\text { Memory }\end{array}$ & & & & & -.319 & & & & & \\
\hline $\begin{array}{l}\text { Prospective } \\
\text { Memory }\end{array}$ & & & & & & & & & & -.348 \\
\hline $\begin{array}{l}\text { Oral } \\
\text { Language: } \\
\text { Inferential } \\
\text { Processing }\end{array}$ & & & -.387 & & & .411 & .399 & & -.466 & \\
\hline $\begin{array}{l}\text { Written } \\
\text { Language: } \\
\text { Reading aloud }\end{array}$ & & -.380 & & & & & & & & -.390 \\
\hline $\begin{array}{l}\text { Executive } \\
\text { Functions: } \\
\text { Verbal } \\
\text { Fluency }\end{array}$ & & .397 & & & & & & & & .363 \\
\hline
\end{tabular}

Note . Abbreviations: Num. $=$ Number, Adm. $=$ Administered, Resp. $=$ Responses, Concept. $=$ Conceptual, Cat. $=$ Category, count. $=$ counting, recog. $=$ recognition, order. $=$ ordering.

${ }^{*} p<.05$

The results also suggest a relationship between the tasks that involve sustained attention, prospective memory and verbal fluency in NEUPSILIN and the EF scores of WCST. However, the results showed correlations of moderate intensity, not reaching strong to moderate intensity indexes as previewed. Results different from the initial hypotheses were found, such as significant correlations between WCST scores and tasks that measure components of episodic-semantic memory, oral language (inferential processing) and written language (reading aloud).

The correlations direction occurred as expected with the WCST scores, such as total number of trails administered, total number of errors, perseverative responses, trials to complete the first category, non-perseverative errors and failure to maintain set assuming negative correlations with NEUPSILIN scores, since the greater the scores, the worse the performance in NEUPSILIN tasks. This means that persons who present high punctuations in these WCST scores, which represent deficits in executive functions, also have worse performance in NEUPSILIN subtests. The scores number of completed categories, total number of correct responses and conceptual level responses establish positive correlations with NEUPSILIN scores, considering that the greater punctuation in these indexes, the better the performance in the NEUPSILIN tasks.

Exceptions to these rules occurred in the correlations between the total number of correct responses of WCST and the reading aloud task of NEUPSILIN, where a negative correlation was observed, as well as in the correlation between non-perseverative errors of WCST and ascendent ordering of digits of NEUPSILIN, with a positive correlation, and lastly in the association between failure to maintain set of WCST and verbal fluency (number of words evoked in one minute) of NEUPSILIN, with a positive sign, too. These unexpected results, as well as those which corroborated the initial hypothesis of the study, will be discussed in the following paragraphs, referring to the evaluated cognitive functions. 
Yates, D. B., Zibetti, M. R., Pawlowski, J., Salles, J. F., Parente, M. A. M. P., Argimon, I. L., Fonseca, R. P. \& Trentini, C. M. (2013). WCST and NEUPSILIN: Relationships among Executive Functions, Attention, Memory and Language.

Amongst the results which corroborated the initial hypotheses, there are correlations between the reverse counting (sustained attention) of NEUPSILIN and trials to complete the first category of WCST, between ascendent ordering digits and several scores of WCST and between the short-term visual memory of NEUPSILIN and perseverative errors of WCST, reinforcing the relationship between working memory and executive functions. According to McCabe et al. (2010), in the concept of executive attention, two functions of the central executive are measured by working memory tasks. The first function is the ability to keep an objective in active state during the task, also a crucial capacity for the executive functions (Banich, 2009; Duncan et al., 1996). The second function is the ability to overcome interference, particularly when there is a conflict between a prepotent response and the task demands, another important capacity for the executive functions (Persson \& Reuter-Lorenz, 2008).

The tasks of reverse counting, ascendent ordering of digits and short-term visual memory demand updating and maintenance of the objectives in the working memory and the inhibition of distractors and automatic behaviors. In the WCST, these abilities are also required when the examinee must discover the rule through the examiner's feedback, keeping his attention on the aim of succeeding in the combinations and inhibiting the tendency of combining the cards using another rule instead of the required one. Similarly, Lehto et al. (2003) found a moderate negative association between the backward digit span task (similar to the reverse counting) and the number of trials to complete the first category of WCST. In the authors' correlation study, it was concluded that the WCST performance depends on the capacity of the working memory.

Concerning the ascendent ordering of digits, Sair, Welsh-Bohmer, Wagner and Steffens (2006) considered the task as a working memory measure conducted by the central executive system, being considered a good executive functioning measure. This task had moderate negative correlations with the scores total number of trials administered, total number of errors, perseverative responses and errors, which indicate the individual's inability to discover the current rule and combine the cards according to the examiner's feedback in the WCST.

The ascendent ordering of digits of NEUPSILIN also had a positive correlation with the number of completed categories, an efficiency score of shifting. Curiously, the ascendent ordering of digits of NEUPSILIN also obtained a moderate and positive correlation with the non-perseverative errors score. This score refers to errors which do not present a perseverative nature, that is, which do not repeat the same kind of error, usually related to the persistence (non-resistance to interference) in the same type of combination done with the preceding category. It is suggested as a hypothesis that those individuals who presented a greater number of non-perseverative errors would possibly have a greater efficiency in the capacity of inhibition to inter- ference, and because of it they would also have a positive performance in the ascendent ordering of digits.

The occurrence of a negative correlation between the short-term visual memory task of NEUPSILIN and the WCST perseverative errors score was observed. The short-term visual memory task involves memorizing an abstract figure and after three seconds recognizing it between three similar figures. In its turn, the score of perseverative errors is an index of the persistence in the same pattern of errors, contrary to the examiner's feedback, demonstrating little mental flexibility, little efficiency to keep the objective of succeeding in the combinations and high susceptibility to interference, presented in the form of the previous category. Miyake et al. (2000) showed that the visual-spatial working memory, the central executive and the spatial abilities present a close relationship. Even more, the authors claim that the storage of visual-spatial information is highly dependent on executive functioning or attentional control. However, the results found in this study are of weak intensity, pointing to the same relationship between visual-spatial storage and $\mathrm{EF}$, but without the intensity indicated in literature. The reason for this difference of correlation intensity is that the task applied by Miyake et al. (2000) is more complex than the one in NEUPSILIN, recruiting, perhaps, more frontal areas.

Like the short-term visual memory, the face recognition task of NEUPSILIN involves perception and visual memory storing. However, this task presents two faces that need to be further recognized amongst four drawn faces. The aim is to find the initially presented faces and to overcome the interference from the distractor faces in the recognition. In this task, it was observed a moderate and negative correlation with the non-perseverative errors scores of WCST, indicating that errors caused by other reasons instead of persistence on an incorrect combination pattern seem to be more associated to faces recognition deficit. Negative weak correlations were also observed between face recognition scores, total number of trials administered and total number of errors. A weak and positive association of the face recognition task occurred with the number of completed categories score of WCST. These weak to moderate relationships within the expected direction may indicate that attention and visual perception of complex stimuli help in concepts formation and in insight capacity necessary for a good WCST performance. It must be noted that both short-term visual memory and face recognition task use visual processing and it is possible that the correlations with the WCST scores also may be explained by the nature of the task, since the WCST uses visual stimuli. Besides, a dissociation is highlighted with the short-term visual memory task, in which correlation occurred with the perseverative errors score, and with the faces recognition task, in which correlation occurred with the non-perseverative errors score. Considering that the first task involves geometrical forms, like the WCST, this similarity may explain its correlations with perseverative 
errors, which mistakes are necessarily linked to the color, form or number of the figures. On the other hand, the face recognition figures are from another kind, which uses a more complex perceptive process, what might explain the correlation with a score of errors of another nature (non-perseverative errors). It is probable that the face recognition task involves the ability to cognitively represent oneself and others. This ability is related to the executive functions and the pre-frontal cortex (Decety $\&$ Sommerville, 2003). The pre-frontal areas activation, both in face recognition and WCST, could justify the correlation between these two tasks. In fact, neuroimaging studies point that theory of mind tasks (which involve face recognition) and executive functions generate similar activations in the pre-frontal medial cortex (specifically in the frontopolar cortex). However, damage to the temporo-parietal region can cause deficiency in several aspects of self-processing, including face recognition. Such patterns of activation explain the weak to moderate correlations between the face recognition task and the WCST scores, considering that they are related functions, but not the same construct.

It was also possible to observe the negative correlations between the delayed recall of the verbal episodic-semantic memory task of NEUPSILIN and the measures of the total number of trials administered, total number of errors and number of trials to complete the first category of WCST. That is, the better the performance in the delayed recall, the less cards the participant used, for both completing the first category and finishing the test. In the NEUPSILIN task, the delayed recall involves remembering the words presented 15 minutes earlier, spontaneously. It can be supposed that memory in the WCST is necessary for not repeating the previous category. These tasks seem to have ecological validity since so many tests of word recall (such as the California Verbal Learning Test), as well as the WCST, are able to predict the kind of work position occupied by patients with neurological injury (Kibby, Schmitter-Edgecombe, \& Long, 1998), assuming there is a relationship between them. Romine and Reynolds (2004) highlight the participation of frontal functions in temporal organization of memories, both retrospectively and prospectively.

The present study found a negative correlation between the performance obtained in the prospective memory task of NEUPSILIN and the score of failure to maintain set of the WCST. This means that participants who made greater scores in failure to maintain set had a worse performance in the prospective memory task. From the point of view of the latent structure of WCST, this score normally forms a unique factor associated to memory, motivation and attention (Greve et al., 1998), constructs on which depend the performance of the prospective memory task. Nyhus and Barceló (2009) suggest that the feedback interpretation in the WCST may reflect the anticipated preparation of future acts, which would depend on a memory that would be activated in the future, as in the prospective one. Thus, the results show that the difficulty of remembering intentions that shall be made in the future (prospective memory) damages the maintenance of the set in the WCST. There are other evidences which support the relationship between the prospective memory and the frontal lobe of the brain, among them: (a) empiric: the cognitive decline related to aging occurs similarly in tasks which evaluate executive function and prospective memory (Zibetti et al., 2010), (b) neuroimaging: neuroanatomical evidences suggest frontal activation in prospective memory tasks (Kliegel, Phillips, Lwemke, \& Kopp, 2005), (c) functional: it was observed a relationship between adherence to medicine (task dependent on prospective memory) and good performance in tasks that evaluate executive functions (Insel, Morrow, Brewer, \& Figueiredo, 2006).

Also significant were the correlations between the scores of the WCST and the result of the NEUPSILIN task that evaluates the language inferential processing. This task consists on the explanation of the meaning of one proverb and two metaphors. Positive correlations were observed with number of completed categories and of conceptual level responses, which are respectively an indication of mental flexibility and a measure of mental concept formation. Negative correlations were observed between the inferential processing and the scores total number of errors and non-perseverative errors of the WCST. These correlations were expected, since the WCST was created as a measure of abstract thought required to comprehend inferences.

Therefore, generally, the associations found between EF and inferential processing measures reinforce the notion that, for comprehending non-literal linguistic units, abstraction abilities and mental flexibility are required. Coelho, Lilles and Duffy (1995) observed a correlation between measures of story structure and the quantity of perseverative errors (as a specific factor of the WCST). Besides, the formation of concepts in WCST seems dependent on the storage capacity of the phonological loop in working memory, as the performance is reduced when an articulatory suppression task is applied in parallel to the test (Cinan \& Tänor, 2002). Both results suggest that if other more complex language tasks were included, as discursive stimuli that demanded processing of implicit language, the correlation with the WCST scores should be even greater.

Another point made by those results found lead to discuss the fact that, although the WCST involves visual stimuli and the oral language task (inferential processing) of NEUPSILIN involves verbal syntactic stimuli, both seem to request a base executive processing. In this sense, Siebörger, Ferstl and Von Cramon (2007) used a version of WCST paradigm with words in a study with functional magnetic resonance. Activation in areas of attentional switching (cortico-striatal circuit) as well as of working memory (caudate nucleus, for example) were found. These 
Yates, D. B., Zibetti, M. R., Pawlowski, J., Salles, J. F., Parente, M. A. M. P., Argimon, I. L., Fonseca, R. P. \& Trentini, C. M. (2013). WCST and NEUPSILIN: Relationships among Executive Functions, Attention, Memory and Language.

results suggest that abstraction mechanisms, insight formation and mental flexibility tend to be amodal (without a visual or verbal base). These mechanisms can explain the correlation between the inferential processing of non-literal sentences and scores of the WCST.

The executive functions are a complex range of several cognitive processes that interact with other cognitive functions, for example, memory, language and attention. Therefore, distinct tasks like verbal fluency of spelling category and the WCST are considered evaluation measures of executive functions (Ardila, Piñeda, \& Rosseli, 2000; Lezak et al., 2004). In this study, there was a correlation between the total number of correct responses of WCST and the score obtained in the verbal fluency of NEUPSILIN. Generally, this WCST score demands the discovery of an adequate answer through feedback, an adequate response and the strategy maintenance afterwards, until the next change of rule, when the process starts again. The verbal fluency with spelling criteria task demands the maintenance of the presented rule and the inhibition of the interference words (not requested by the examiner). Both processes are necessary for the satisfactory execution of the WCST, justifying the positive correlation. Besides, the creation of the semantic strategies in the task of verbal fluency qualitatively seems to strengthen the speed of the words spoken, the same way that the maintenance of the correct strategy in WCST produces success.

Yet, there was an unexpected positive correlation between the failure to maintain set of the WCST and the verbal fluency task of the NEUPSILIN. A possible explanation for this is that a low score in the failure to maintain set requires a good inhibitory capacity of the individual, because the examinee must maintain in his mind the current category and avoid making incongruent combinations. On the other hand, in the verbal fluency task, where the inhibitory capacity is also required, the excess of such control could reduce the usage of words, when the participant is too focused on the rule.

Finally, it is believed that in the reading aloud task of NEUPSILIN, a spurious correlation occurred. Specifically, the association with the total number of correct responses scores of the WCST happened in the negative way, which would mean that a better WCST performance would be associated to a worse performance in reading words. One possible explanation for this unexpected relationship is that the total number of correct responses can only be interpreted as good executive functioning if the participant succeeds in discovering the categories and completing them. If that does not occur, he may still have many successes as many cards will be used, which does not mean he has a good executive performance. There was also a negative association (expected direction) with the failure to maintain set score of WCST. However, there is no clear explanation for the relationship between reading aloud and the incapacity of making correct sequential combinations in the WCST; additionally, both involve visual-perceptual abilities. However, relationships between the two functions have been found so far, like in the studies of Marzocchi et al. (2008) and Zamo (2011), where groups facing reading difficulties presented inferior performance in executive function tasks, like verbal fluency and go-no-go (Zamo, 2011). Sluis, Jong and Leij (2007) affirm that the executive functions underlie a series of cognitive functions like reasoning, reading and arithmetic.

\section{Conclusion}

The study investigated the relationship between the scores generated by the WCST and the results from diverse neuropsychological tasks evaluated by NEUPSILIN. The hypothesis that strong correlations would happen between the performances obtained in the WCST and the executive functions (verbal fluency and problem solving), working memory, prospective memory and attention tasks of the NEUPSILIN, by the approximations generated in the concept of executive attention (McCabe et al., 2010), was partially corroborated. This is because there was no difference in the strength of the correlation between those tasks in comparison with others that had significant correlations. However, the majority of the correlations mentioned had an expected (positive or negative) direction with at least one WCST score. This result denotes that the theoretical and methodological relationship between the scores obtained in those tasks is not idiosyncratic, even if the common component is not representative as in the hypothesis.

To justify the correlations found, a wide spectrum of information was analyzed, like the neuroanatomical relationships, the similarities between the cognitive processing in the tasks' execution and the psychometric data about the tests structures. Despite the methodological stringency, one limitation of the study is the sample size, which may have influenced the correlation intensity, as being a small sample, it may have shown less variability, harming the correlations result.

Furthermore, the range of studies which aim to investigate the relationship between executive functions forms of evaluation and other tests is great, but the theoretical and methodological advances should raise the update of the explaining paradigms, with the aim of a more enhanced comprehension of the underlying aspects of the relationships between the tests. For example, more studies relating specific executive components measured in the WCST and cognitive components of other neuropsychological functions involving more complex linguistic stimuli, like oral or written speech, are necessary.

Generally, besides the interesting clinical implications of the inter-tests relationship for the neuropsychological assessment, the preliminary results found in the current study also can be considered supplemental evidence of construct validity of some NEUPSILIN subtests, due to their correlations with the WCST scores, an instrument acknowledged as valid for the EF assessment. 


\section{References}

Ardila, A. (2008). On the evolutionary origins of executive functions. Brain and Cognition, 68, 92-99.

Ardila, A., Piñeda, D., \& Rosseli, M. (2000). Correlation between Intelligence Test Scores and Executive Function Measures. Archives of Clinical Neuropsychology, 15(1), 31-36.

Ashendorf, L., \& McCaffrey, R. J. (2008). Exploring age-related decline on the Wisconsin Card Sorting Test. The Clinical Neuropsychologist, 22, 262-272.

Ávila, K. N. (2007). Modified Wisconsin Card Sorting Test (MCST): Desempenho de idosos com diferentes níveis de escolaridade. Psicologia Hospitalar (São Paulo), 5(2), 21-35.

Baldo, J. V, Dronkers, N. F., Wilkins, D., Ludyb, C., Raskina, P., \& Kima, J. (2005). Is problem solving dependent on language? Brain and Language, 92, 240-250.

Balota, D. A., Cortese, M. J., Duchek, J. M., Adams, D., Roediger, H. L., McDermott, K. B., \& Yerys, B. E. (1999). Veridical and false memories in healthy older adults and in dementia of the Alzheimer's type. Cognitive Neuropsychology, 16, 361-384.

Banich, M. T. (2009). Executive function: The search for an integrated account. Current Directions in Psychological Science, 18, 89-94.

Blair, C., Zelazo, P. D., \& Greenberg, M. (2005). The assessment of executive function in early childhood: Prospects and progress. Developmental Neuropsychology, 28, 561-571.

Chan, R., Shum, D., Toulopoulou, T., \& Chen, E. (2008). Assessment of executive functions: Review or instruments and identification of critical issues. Archives of Clinical Neuropychology, 23, 201-216.

Cinan, S. (2006). Age-related changes in concept formation, rule switching, and perseverative behaviors: A study using WCST with 12 unidimensional target cards. Cognitive Development, 21, 377-382.

Cinan, S., \& Tänor, O. O. (2002). An attempt to discriminate different types of executive functions in the Wisconsin Card Sorting Test. Memory, 10(4), 277-289

Coelho, C. A., Lilles, B. Z., \& Duffy, R. J. (1995). Impairments of discourse abilities and executive functions in traumatically brain-injured adults. Brain Injury, 9(5), 471-477.

Cunha, J. A., Trentini, C. M., Argimon, I., Oliveira, M. S., Werlang, B. G., \& Prieb, R. G. G. (2005). Adaptação e padronização brasileira do Manual do Teste Wisconsin de Classificação de Cartas. São Paulo, SP: Casa do Psicólogo.

Dancey, C. P., \& Reidy, J. (2006). Estatística sem Matemática para Psicologia. Porto Alegre, RS: Artmed.

Decety, J., \& Sommerville, J. A. (2003). Shared representations between self and other: A social cognitive neuroscience view. TRENDS in Cognitive Sciences, 7(12), 527-533.

Delis, D. C., Kaplan, E., \& Kramer, J. H. (2001). Delis-Kaplan Executive Function System. San Antonio, TX: Psychological Corporation.

Depue, B. E., Banich, M. T., \& Curran, T. (2006). Suppression of emotional and non-emotional content in memory: Effects of repetition on cognitive control. Psychological Science, 17, 441-447.

Duncan, J., Burgess, P., \& Emslie, H. (1995). Fluid intelligence after frontal lobe lesions. Neuropsychologia, 33, 261-268.

Duncan, J., Emslie, H., Williams, P., Johnson, R., \& Freer, C. (1996). Intelligence and the frontal lobe: The organization of goal-directed behavior. Cognitive Psychology, 30, 257-303.

Eling, P., Derckx, K., \& Maes, R. (2008). On the historical and conceptual background of the Wisconsin Card Sorting Test. Brain and Cognition, 67, 247-253.
Engle, R. W. (2002). Working Memory Capacity as Executive Attention. Current Directions in Psychological Science, 11, 19-23.

Engle, R. W., Tuholski, S. W., Laughlin, J. E., \& Conway, A. R. A. (1999). Working memory, short-term memory and general fluid intelligence: A latent variable approach. Journal of Experimental Psychology: General, 128, 309-331.

Fernandez-Duque, D., \& Posner, M. I. (2001). Brain imaging of attentional networks in normal and pathological states. Journal of Clinical and Experimental Neuropsychology, 23, 74-93.

Fonseca, R. P., Sales, J. F., \& Parente, M. A. M. P. (2009). Instrumento de avaliação neuropsicológica breve: NEUPSILIN. São Paulo, SP: Vetor.

Friedman, N. P., \& Miyake, A. (2004). The relations among inhibition and interference control functions: A latent-variable analysis. Journal of Experimental Psychology: General, 133, 101-135.

Greve, K. W., Ingram, F., \& Bianchini, K. J. (1998). Latent structure of the Wisconsin Card Sorting Test in a clinical sample. Archives of Clinical Neuropsychology, 13(7), 597-609.

Greve, K. W., Love, J. M., Sherwin, E., Mathias, C. W., Ramzinski, P., \& Levy, J. (2002). Wisconsin Card Sorting Test in chronic severe traumatic brain injury: Factor structure and performance subgroups. Brain Injury, 16, 29-40.

Greve, K. W., Williams, M. C., Haas, W. G., Littell, R. R., \& Reinoso, C. (1996). The role of attention in Wisconsin Card Sorting Test performance. Archives of Clinical Neuropsychology, 11(3), 215-222.

Heaton, R. K., Chelune, G. J., Talley, J. L., Kay, G. G., \& Curtiss, G. (1993). Wisconsin Card Sorting Test Manual (Revised and expanded). Odessa, FL: Psychological Assessment Resources.

Hull, R., Martin, R. C., Beier, M. E., Lane, D., \& Hamilton, A. C. (2008). Executive function in older adults: A structural equation modeling approach. Neuropsychology, 22, 508-522.

Insel, K., Morrow, D., Brewer, B., \& Figueredo A. (2006). Executive Function, Working Memory, and Medication Adherence among Older Adults. Journal of Gerontology: Psychological Sciences, 61(2), 102-107.

Kane, M. J., \& Engle, R. W. (2000). WM capacity, proactive interference, and divided attention: Limits on long-term memory retrieval. Journal of Experimental Psychology: Learning, Memory, and Cognition, 26, 336-358.

Kibby, M. Y., Schmitter-Edgecombe M., \& Long, C. J. (1998). Ecological Validity of Neuropsychological Tests: Focus on the California Verbal Learning Test and the Wisconsin Card Sorting Test. Archives of Clinical Neuropsychology, 13(6), 523-534.

Kliegel, M., Phillips, L. H., Lwemke, U., \& Kopp, U. A. (2005). Planning and realisation of complex intentions in patients with Parkinson's disease. Journal of Neurology, Neurosurgery and Psychiatry, 76, 1501-1505.

Lehto, J. (1996). Are executive function tests dependent on working memory capacity? Quarterly Journal of Experimental Psychology, 49A, 29-50.

Lehto, J. E., Juujärvi, P., Kooistra, L., \& Pulkkinen, L. (2003). Dimensions of executive functioning: Evidence from children British Journal of Developmental Psychology, 21, 59-80.

Lezak, M. D, Howieson, D. B., \& Loring, D. W. (2004). Neuropsychological Assessment ( $4^{\text {th }}$ ed.). New York: Oxford University Press

Lie, C., Specht, K., Marshall, J. C., \& Fink, G. (2006). Using fMRI to decompose the neural process underlyng the Wisconsin Card Sorting Test. NeuroImage, 30, 1038-1049. 
Yates, D. B., Zibetti, M. R., Pawlowski, J., Salles, J. F., Parente, M. A. M. P., Argimon, I. L., Fonseca, R. P. \& Trentini, C. M. (2013). WCST and NEUPSILIN: Relationships among Executive Functions, Attention, Memory and Language.

Logan, G. D. (2003). Executive control of thought and action: In search of the wild homunculus. Current Directions in Psychological Science, 12, 45-48.

Mansur, J., \& Monteiro, M. G. (1983). Validation of the "CAGE" alcoholism screening test in a Brazilian psychiatric inpatient hospital setting. Brazil Journal Medical and Biological Research, 16(3), 215-218.

Marzocchi, G., Oosterlaan, J., Zuddas, A., Cavolina, P., Geurts, H., Redigolo, D., ...Sergeant, J. (2008). Contrasting deficits on executive functions between ADHD and reading disabled children. Journal of Child Psychology and Psychiatry, 49(5), 543-552.

McCabe, D. P., Roediger, H. L., McDaniel, M. A., Balota, D. A., \& Hambrick, D. Z. (2010). The Relationship between Working Memory Capacity and Executive Functioning: Evidence for a Common Executive Attention Construct. Neuropsychology, 24(2), 222-243.

McVay, J. C., \& Kane, M. J. (2009). Conducting the train of thought: Working memory capacity, goal neglect, and mind wandering in an executive-control task. Journal of Experimental Psychology: Learning, Memory, and Cognition, 35, 196-204.

Miguel, F. K. (2005). Teste Wisconsin de Classificação de Cartas. Avaliação Psicológica 4(2), 203-204.

Miyake, A., Friedman, N. P., Emerson, M. J., Witzki, A. H., Howerter, A., \& Wager, T. D. (2000). The Unity and Diversity of Executive Functions and Their Contributions to Complex "Frontal Lobe" Tasks: A Latent Variable Analysis. Cognitive Psychology, 41, 49-100.

Nelson, H. E. (1976). A modified card sorting test sensitive to frontal lobe defects. Cortex, 12(4), 313-324.

Nyhus, E., \& Barceló, F. (2009). The Wisconsin Card Sorting Test and the cognitive assessment of prefrontal executive functions: A critical update. Brain and Cognition, 71, 437451.

Pawlowski, J. (2007). Evidências de Validade e Fidedignidade do Instrumento de Avaliação Neuropsicológica Breve Neupsilin (Dissertação de Mestrado em Psicologia, Instituto de Psicologia, Universidade Federal do Rio Grande do Sul, Porto Alegre, RS, Brasil).

Pawlowski, J., Fonseca, R. P., Salles, J. F., Parente, M. A. M. P., \& Bandeira, D. R. (2008). Evidências de validade do Instrumento de Avaliação Neuropsicológica Breve Neupsilin. Arquivos Brasileiros de Psicologia, 60(2), 101-116.

Persson, J., \& Reuter-Lorenz, P. A. (2008). Gaining control: Training executive function and far transfer of the ability to resolve interference. Psychological Science, 19, 881-888.

Romine, C. B., \& Reynolds, C. R. (2004). Sequential Memory: A Developmental Perspective on its Relation to Frontal Lobe Functioning. Neuropsychology Review, 14(1), 43-64.

Sair, H. I., Welsh-Bohmer, K. A., Wagner, H. R., \& Steffens, D. C. (2006). Ascending Digits Task as a Measure of Executive Function in Geriatric Depression. The Journal of Neuropsychiatry and Clinical Neurosciences, 18, 117-120.

Salthouse, T. A. (2005). Relations between cognitive abilities and measures of executive functioning. Neuropsychology, 19(4), 532-545.

Salthouse, T. A., Atkinson, T. M., \& Berish, D. E. (2003). Executive functioning as a potential mediator of age-related cognitive decline in normal adults. Journal of Experimental Psychology: General, 132, 566-594.
Siebörger, F. T., Ferstl, E. C., \& Von Cramon, D. Y. (2007). Making sense of nonsense: An fMRI study of task induced inference processes during discourse comprehension. Brain Research, 1166, 77-91.

Sluis, V. der S., Jong, de P. F., \& Leij, V. der A. (2007). Executive functioning in children, and its relations with reasoning, reading, and arithmetic. Intelligence, 35, 427-449.

Stuss, D. T., \& Alexander, M. P. (2000). Executive functions and the frontal lobes: A conceptual view. Psychological Research, 63, 289-298.

Trentini, C. M., \& Argimon, I. I. (2008). O uso do teste Wisconsin para a avaliação das funções executivas. In K. Z. Ortiz (Ed.), Avaliação neuropsicológica: Panorama interdisciplinar dos estudos na normatização e validação de instrumentos no Brasil (pp. 200-207). São Paulo, SP: Vetor.

Trentini, C. M., Argimon, I. I., Oliveira, M. S., \& Werlang, B. G. (2010). Teste Wisconsin de Classificação de Cartas: Versão para idosos - Manual Técnico. São Paulo, SP: Casa do Psicólogo.

Verdejo-García, A., \& Bechara, A. (2010). Neuropsicología de las funciones ejecutivas. Psicothema, 22(2), 227-235.

Zamo, R. (2011). Avaliação neuropsicológica de crianças com dificuldades de leitura através do Instrumento de Avaliação Neuropsicológica Breve Infantil NEUPSILIN-INF (Dissertação de mestrado, Programa de Pós-Graduação em Psicologia, Instituto de Psicologia, Universidade Federal do Rio Grande do Sul, Porto Alegre, RS, Brasil).

Zibetti, M. R., Gindri, G., Pawlowski, J., Salles, J. F., Bandeira, D. R., Parente, M. A. M. P., ...Fonseca, R. P. (2010). Estudo comparativo de funções neuropsicológicas entre grupos etários de 21 a 90 anos. Revista Neuropsicologia Latinoamericana, 2(1), 55-67.
Recebido: $23 / 11 / 2011$

$1^{a}$ revisão: $19 / 02 / 2012$

$2^{a}$ revisão: 04/04/2012

Aceite final: $22 / 06 / 2012$ 